\title{
EL PARALENGUAJE EN EL QUIJOTE: INVENTARIO COMPLETO Y BASES PARA SU ESTUDIO
}

\author{
Fernando Poyatos
}

University of New Brunswick

\section{INTRODUCCIÓN: MODELO BÁSICO PARA EL ESTUDIO DEL PARALENGUAJE CERVANTINO ${ }^{1}$}

El reunir aquí de manera exhaustiva las alusiones explícitas al paralenguaje que Cervantes hizo en el Quijote, lejos de responder a un afán de recuento sin otros fines, intenta promover el estudio de aspectos de

1 Como fuente básica para desarrollar el estudio de este inventario e identificar y describir los muchos y distintos fenómenos paralinguiísticos, remito al lector a mi monografía Paralanguage: Interdisciplinary Approach to Interactive Speech and Sound (Amsterdam/Filadelfia: John Benjamins, 1993) y, en español, a La comunicación no verbal, volumen I: Cultura, lenguaje e interacción; volumen II: Paralenguaje, kinésica e interacción; volumen III: Nuevas perspectivas en novela y teatro y en su traducción (Madrid: Ediciones Istmo, 1994; $2^{\mathrm{a}}$ ed. ampliada, en prep., con el inventario paralinguíístico y el kinésico del Quijote completos, en el volumen III. En español, otros temas afines se encuentran, por ejemplo, en «La comunicación en el discurso y en el texto» (Analecta Malacitana, XIX, I, 1996), «Los silencios en el discurso vivo y 
su obra hasta ahora no estudiados sistemáticamente, como son el paralenguaje y la kinésica con los fines básicos que, dentro de los límites de un artículo, se resumen a continuación.

1. Identificar la presencia explícita de los fenómenos paralingüísticos a través de las descripciones verbales del autor o, los menos, la transcripción ortográfica de esos fenómenos asistida por los medios gráficos de puntuación al alcance del escritor. Por supuesto que a menudo la descripción, sin especificar paralenguaje ni kinésica, se refiere claramente a ambos, por ejemplo en: «Decía esto con tanto brío y denuedo», «con reposo y ademán severo», mientras que el tipo de voz puede evocar los aspectos visuales del discurso ${ }^{2}$.

en la literatura: para el estudio realista del lenguaje y su entorno» (Oralia: Análisis del discurso oral 1 , en prensa) y «El acto de lectura: su realidad verbal-no verbal» (El Extramundi y los Papeles de Iria Flavia, en prensa).

${ }_{2}$ Paralenguaje: las cualidades no verbales de la voz y sus modificadores y emisiones independientes cuasiléxicas - producidas o condicionadas en las zonas comprendidas en las cavidades supraglóticas (desde los labios y nares hasta la faringe), cavidad laríngea y cavidades infraglóticas (pulmones y esófago) hasta los músculos abdominales, así como los silencios momentáneos-, que utilizamos consciente o inconscientemente para apoyar, realzar, debilitar o contradecir los signos verbales, kinésicos, proxémicos, químicos, dérmicos y térmicos, simultáneamente o alternando con ellos, tanto en la interacción como en la no-interacción. Comprende cuatro categorías, aquí sólo identificadas:

(a) cualidades primarias, las más próximas a los elementos suprasegmentales de la estructura linguiística: timbre (personal, cultural, anormal), resonancia (oral, nasal, faríngea, etc.), volumen (personal, cultural, actitudinal), registros (personal, cultural, actitudinal, etc.), campo entonativo (monótono-melódico), duración silábica (alargamiento-acortamiento), tempo (lento-rápido) y ritmo (suave-desigual);

(b) calificadores, también posibles cualidades básicas, pero generalmente distintos tipos de voz debidos a: control respiratorio (aspirada o espirada: “¡Ah!"), control laríngeo (susurrante, áspera, estridente, ronca, etc.), control esofágico (esofágica), control faríngeo (hueca, apagada, etc.), control velofaríngeo (gimoteante, gimiente, etc.), control lingual (retrofleja, velarizada, etc.), control labial (por distensión o contracción de los labios), control mandibular (voz mascullante con la mandíbula cerrada y girando), control articulatorio (ultracorrecta, confusa, etc.), control de tensión articulatoria (tensa, relajada) y control objetual (hablando y comiendo a la vez, o con una pipa en la boca);

(c) diferenciadores, modificadores de las palabras y de sus rasgos suprasegmentales, pero posibles también independientemente como reacciones fisiológicas o emocionales: risa (de afiliación, agresión, tristeza, etc.), llanto (de afiliación, compasión, gozo, ansiedad, etc.), grito (de agresión, dolor, alarma, ritualizado, etc.), suspiro (fisiológico, de placer, nostalgia, sorpresa, alivio, etc.), jadeo (por esfuerzo físico, etc.), bostezo (de fatiga, aburrimiento), tos (fisiológica, de ansiedad, etc.), carraspeo (de tensión, advirtiendo a alguien de algo, etc.), escupir (fisiológico, casual, ritualizado, etc.), eructo (fisiologico, elogioso, actitudinal), hipo (con conductas asociadas) y estornudo (conductas asociadas de carácter cortés, religioso o supersticioso);

(d) alternantes, como 'cuasipalabras', identificables y clasificables fonética y funcionalmente y utilizados tan semánticamente como las palabras, pero la mayoría sin nombres y verbos para designarlos, ni representación gráfica: clics, siseos, bisbiseos, gruñidos, soplos, aspiraciones y espiraciones, carraspeos, ronquidos, "¡Mmmm!", “Mm?”, “iAjá!”, “ßBuh!”, “Ffss”, “¡Psche!”, “jras!”, “¡zas!”, “Brr!”, “Chsss”, “¡tlin!”, ¡Uf!, imitaciones de sonidos, llamadas a animales, etc. 
2. Poder juzgar, por tanto, la riqueza expresiva de los personajes cervantinos - reflejo a su vez del discurso de la época-, según es evocada por su creador. Esta riqueza puede disminuir la inevitable pluralidad de los personajes literarios en cada lectura y por cada lector, ya que, en el caso del Quijote, a don Quijote y a Sancho, por ejemplo, les 'vemos' y 'oímos' lo suficiente para construir en nuestra imaginación unas personas con repertorios que, incluso cuando no se especifican las conductas no verbales, ya nosotros les adjudicamos como a quienes nos son familiares. Lo cual también da pie para diversos tipos de estudios comparados respecto a otros narradores y períodos, empezando por la narrativa del Siglo de Oro.

3. Observar que, por otra parte -como ocurre en cualquier autor-, no podemos ser tan ingenuos como para estar seguros de que siempre son suficientes esas descripciones verbales de las conductas no verbales (paralenguaje o kinésica) para hacer que el lector 'oiga' correctamente las voces de los hablantes de la época original, a quienes Cervantes oía perfectamente en su imaginación porque de hablantes así vivía rodeado. Qué no daríamos por saber cómo sonaba realmente, hace cuatrocientos años, cuando alguien hablaba «con gentil talante y voz reposada», «con mucha humildad», «con mucho entono y gravedad», «con tierno acento», «con tristes acentos», cuando hablaba don Quijote «levantando [...] la voz y con ademán arrogante»; y cómo eran entonces una risa «a socarrón", el "ceceo" cuando «la hija de la ventera le comenzó a cece-

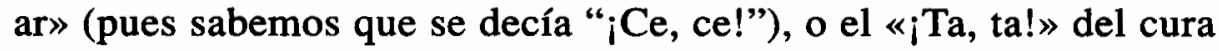
y Sancho. Y qué no daríamos por ver, exactamente como lo veía Cervantes, aquellos gestos, maneras y posturas (realizados, por ejemplo, "con donaire"), condicionados históricamante por la ropa, por las normas sociales (rango, contexto situacional, etc.) y por la evolución de ciertos conceptos sobre nuestra interacción con los demás.

4. Reconocer que las conductas paralingüísticas descritas o representadas evocan en el lector más sensible las conductas kinésicas concurrentes que siempre se dan en el discurso (personal y cultural o subculturalmente diferenciadas), en virtud de la perfecta cohesión existente dentro de la triple estructura lenguaje-paralenguaje-kinésica de nuestro hablar; lo mismo, por supuesto, que la kinésica descrita evoca el paralenguaje cuando ambos se combinan.

5. Reconocer asimismo que las cualidades paralingüísticas descritas por Cervantes se refieren a unas palabras concretas y no a 
otras, dentro de las alternativas de elección con que puede contar el escritor, y que cualquier otra palabra dentro de su repertorio verbal no sonaría igual. Esto quiere decir que el lector de más sensibilidad debe "oírlas" tal como el escritor lo haría, por ejemplo: « Eso no, ¡voto a tal! - -respondió con mucha cólera don Quijote», «iVoto... -y miró al cielo y apretó los dientes- que estoy por hacer un estrago en ti [...]!», «[don Quijote [...] con asaz cólera le dijo:/ —iTan en hora mala supiste rebuznar, Sancho!» Para ello, una ventaja que no todo escritor ofrece es que muy pocas veces describe Cervantes el paralenguaje y la kinésica del discurso - es decir, cómo se dice y cómo se mueve- después de habernos hecho leer lo que dice el personaje $^{3}$.

6. Este captar el cómo se dice lo que se dice nos sugiere inmediatamente la dificultad tan grande que ello ofrece al lector de otra cultura y, aún más, al del texto traducido, para el cual el traductor más responsable debe esforzarse por escoger la palabra que no solamente transmita el mismo significado, sino acústicamente lo más cercana posible al original de la lengua fuente. Por eso, un estudio comparativo lingüístico-paralingüístico-kinésico nos revela tanto las dificultades como los fallos en no evocar precisamente las cualidades sonoras que contiene la lectura de los originales ${ }^{4}$.

7. Por otra parte, el estudio de este inventario paralingüístico - estudio que aquí sólo se pretende sugerir- debe servirnos para reconocer la función importantísima del repertorio paralingüístico de Cervantes como procedimiento tripartita, comunicativo, técnico y estilístico, con que da forma sensible a las personalidades de don Quijote y su escudero 5 .

8. También, tanto en Cervantes como en otros narradores de ésa y otras épocas de la sociedad española, se nos documentan ciertas funciones interactivas de los comportamientos paralinguiísticos idénticas a las de nuestros días en distintas culturas, por ejemplo, la tos para la "preapertura del turno" conversacional: «[Dorotea] después de haber-

3 Véase la discusión detallada de ambas alternativas en nuestro «El acto de lectura..." (El Extramundi, en prensa).

4 Además de los comentarios sobre la traducción contenidos en Poyatos (1994, volumen III), véanse los más concretos y recientes en «Aspects, Problems, and Challenges of Nonverbal Communication in Literary Translation», en F. Poyatos (ed.), Nonverbal Communication in Translation (Amsterdam/Philadelphia: John Benjamins, $1997,17-47)$ y otros trabajos en el mismo volumen.

5 Sobre estas funciones, véase F. Poyatos, 1994, Vol. III, capítulo 6. 
se puesto bien en la silla y prevenídose con toser y hacer otros ademanes, con mucho donaire comenzó a decir: [...]» 6 .

9. A todo esto es preciso añadir que allá donde Cervantes, o cualquier otro narrador, trata de reproducir el discurso de sus personajes, bien a través del paralenguaje o de la kinésica, el lector debe saber reconocer la presencia implícita de lo que no se describe (o describe, en el caso del paralenguaje); es decir, que se trata sencillamente de intuir esa mutua inherencia de ambos sistemas que hace que uno (aunque sea muy ligeramente) siempre se acompañe del otro dentro de lo que es la realidad audiovisual del discurso; aunque no se haga referencia directa a ningunas manifestaciones no verbales, el texto las sugiere de acuerdo con ciertos patrones comunicativos personales y culturales, como se ha indicado ya. Por supuesto, esto último nos lleva una vez más al arriesgado campo del texto traducido, con el peligro de la mala interpretación o de la ausencia total de ella, y no ya de lo no mencionado (lógicamante implícito para el lector nativo), sino de las mismas descripciones verbales del texto.

10. Por último, también pretende este inventario no analítico suscitar más investigación sobre el paralenguaje en nuestros clásicos y en otros períodos; y, como en el caso de los gestos, maneras y posturas (condicionadas por factores más tangibles, como el vestido y las normas de etiqueta), el estudio diacrónico del español hablado en su totalidad verbal-paralinguiística-kinésica, pese a las dificultades a veces insuperables de tal empresa reconstructiva ${ }^{7}$.

\section{INVENTARIO PARALINGÜÍSTICO DEL QUIJOTE}

\section{A. CUALIDADES PRIMARIAS}

\section{Primera Parte}

[Al llegar don Quijote ante las mozas de la venta] alzándose la visera de papelón y descubriendo su seco y polvoroso rostro, con gentil

6 «The magistrate, with a preparatory cough [...] was proceeding to commence his address. [...] with another preparatory cough, he proceeded [...] to pronounce his decision» (Dickens $P P, \mathrm{XXV}$ ). Véanse dos modelos detallados (con ejemplos literarios) para el estudio de la conversación y de la interacción, en Poyatos 1994, volumen I, capítulo 7, y volumen II, capítulo 7, respectivamente.

7 La kinésica del Quijote aparecerá en un inventario completo similar a éste en esta misma revista. He de advertir que en el volumen III de La comunicación no verbal (Poyatos 1994), debe leerse «buena parte de las conductas kinésicas» donde, por error, dice «[aquí] se registran todas las conductas kinésicas» (pág. 135). 
talante y voz reposada les dijo:/ - No fuyan las vuestras mercedes ni teman desaguisado (I, II)

[don Quijote a aquellas mozas de la venta, imaginándolas] principales señoras y damas de aquel castillo, les dijo con mucho donaire:/ -Nunca fuera caballero de damas tan bien servido [...] (I, II)

don Quijote [...] en viéndole llegar [al ventero], en voz alta le dijo:/ —OOh tú $[\ldots]$ ! (I, III) ${ }^{8}$

-Pero de vosotros, soez y baja canalla, no hago caso alguno [...]./ Decía esto con tanto brío y denuedo, que infundió un terrible temor en los que le acometían (I, III)

levantando don Quijote la voz y con ademán arrogante dijo:/ -Todo el mundo se tenga, si todo el mundo no confiesa que no hay en el mundo doncella más hermosa que [...] Dulcinea del Toboso (I, IV)

[el labrador] comenzó a decir a voces:/ Abran vuestras mercedes al señor Valdovinos y al señor marqués de Mantua $(I, V)$

comenzó a dar voces don Quijote, diciendo:/ —Aquí, aquí, valerosos caballeros (I, VII)

[don Quijote] se puso en la mitad del camino por donde los frailes venían [...] en alta voz dijo: $\backslash$-Gente endiablada y descomunal [...] (I, VIII)

[cuando las señoras le piden que perdone la vida al vizcaíno] A lo cual don Quijote respondió con mucho entono y gravedad: - Por cierto, fermosas señoras $[\ldots](\mathrm{I}, \mathrm{IX})$

apenas la hubo visto [la pastora Marcela] Ambrosio, cuando con muestras de ánimo indignado le dijo:/ — $i$ Vienes a ver, por ventura, ¡oh fiero basilisco destas montañas! [...] (I, XIV)

[don Quijote] puesta la mano en el puño de su espada, en altas e inteligibles voces, dijo:/ - Ningua persona [....] se atreva a seguir a la hermosa Marcela, so pena de caer en la furiosa indignación mía (I, XIV)

8 Observemos cómo Cervante utiliza el signo de exclamación tanto cuando ha dicho que el personaje habla «en voz alta», «daba voces», «dando una gran voz», «con grandes voces», «a voces», «alzó la voz», etc., como cuando el signo mismo lo indica; mientras que otras veces describe el discurso también como «a grandes voces», o [levantando la voz todo lo que pudo», pero no lo utiliza; por otra parte, podrían combinarse muy justificadamente la exclamación y la interrogación cuando esta última se anuncia como «dando una gran voz». 
[el cuadrillero, creyendo muerto a don Quijote] con esta sospecha reforzó la voz, diciendo:/ — ¿Ciérrese la puerta de la venta! (I, XVI)

[don Quijote] llamó al ventero, y, con voz muy reposada y grave, le dijo:/ - Muchas y muy grandes son las mercedes, señor alcaide, que en este vuestro castillo he recebido (I, XVII)

el ventero le respondió con el mismo sosiego (I, XVII)

[don Quijote] con voz levantada comenzó a decir:/ -Aquel caballero que allí ves de las armas jaldes [...] (I, XVIII)

Diole voces Sancho [a don Quijote], diciéndole:/ — ¡Vuélvase vuestra merced [...] que son carneros y ovejas las que va a embestir! (I, XVIII)

Ni por ésas volvió don Quijote; antes, en altas voces, iba diciendo:/ — ¿Ea, caballeros [...]! (I, XVIII)

[don Quijote] cuando los vio cerca [a los encamisados] alzó la voz y dijo:/ -Deteneos, caballeros (I, XIX)

se llegó Sancho Panza al oído de su señor y muy pasito le dijo:/ -Bien puede vuestra merced, señor, concederle el don que pide (I. XXIX)

[Sancho] con grande enojo, y alzando la voz, dijo: - Voto a mí, y juro a mí, que no tiene vuestra merced, señor don Quijote, cabal juicio (I, XXX)

[Dorotea] recogiendo sus cabellos [...] haciéndose fuerza por detener algunas lágrimas que a los ojos se le venían, con voz reposada y clara comenzó la historia de su vida (I, XXVIII)

La ventera, ventero, su hija y Maritornes [...] les salieron a recibir con muestras de mucha alegría, y él las recibió con grave continente y aplauso (I, XXXII)

Oyó estas razones Cardenio [...]; y así] las oyó, dando una gran voz, dijo:/ — ¡Válgame Dios! ¿Qué es esto que oigo? (I, XXXVI)

don Quijote [...] con mucha gravedad y reposo, puestos los ojos en la hermosa Dorotea, dijo:/ —Estoy informado, hermosa señora, deste mi escudero, que vuestra grandeza [..] (I, XXXVII)

Dorotea [...] con mucho donaire y gravedad le respondió:/ - [...] valeroso caballero de la Triste Figura (I, XXXVII) 
[el cautivo] con voz agradable y reposada comenzó a decir de esta manera:/ —En un lugar de las montañas de León [...] (I, XXXVIIIXXXIX)

Clara, temerosa de que Luscinda no la oyese, abrazando estrechamente a Dorotea, puso su boca tan junto del oído de Dorotea, que seguramente podía hablar sin ser de otro sentido (I, XLIII)

$\mathrm{Al}$ mozo se le vinieron las lágrimas a los ojos, y no pudo responder palabra (I, XLIV)

A lo cual respondió don Quijote, muy de espacio y con mucha flema:/ -Fermosa doncella [...] (I, XLIV)

[cuando Sancho le da un mojicón] el barbero [...] alzó la voz de tal manera [...]:/ —AAquí del rey y de la justicia [...]! (I, XLIV)

don Fernando tomando los votos de unos en otros, hablándoles al oído para que en secreto declarasen [...] Y después [...] dijo en alta voz:/ —El caso es, buen hombre, que [...] (I, XLV)

[un cuadrillero] poniéndosele a leer de espacio [un pergamino que hablaba de don Quijote], porque no era buen lector, a cada palabra que leía ponía los ojos en don Quijote (I, XLV)

[el cuadrillero] asió a don Quijote del cuello fuertemente, que no le dejaba alentar, y a grandes voces decía:/ —Favor a la Santa Hermandad! (I, XLV)

Reíase de oír estas razones [de los cuadrilleros que querían llevársele] don Quijote, y con mucho sosiego dijo:/ —Venid acá, gente soez y malnacida (I, XLV)

- ¡Válame Nuestra Señora!-respondió Sancho, dando una gran voz (I, XLVIII)

[don Quijote] subió sobre Rocinante y embrazó su adarga, y dijo en alta voz a todos [...]:/ —Agora, valerosa compañía, veredes [...] (I, LII)

Con las voces y gemidos de Sancho revivió don Quijote (I, LII)

Cosa de lástima fue oír los gritos que las dos buenas señoras alzaron (I, LII)

Aquí alzaron las dos de nuevo los gritos al cielo (I, LII) 


\section{Segunda Parte}

la ama y la sobrina [...] daban grandes voces en el patio (II, II)

Llegó Sansón, socarrón famoso, y abrazándole [a don Quijote] como la vez primera, y con voz levantada le dijo:/ — iOh flor de la andante caballería! (II, VII)

[don Quijote] volvió a la carreta, que ya estaba bien cerca del pueblo. Iba dando voces, diciendo:/ —Deteneos, esperad [...] (II, XI)

el Caballero del Bosque [..] dijo con voz sonora y comedida:/ ¿Quién va allá? (II, XII)

Anda despacio; habla con reposo; pero no de manera que parezca que te escuchas a ti mismo; que toda afectación es mala (II, XIII)

[el Caballero del Bosque] con voz asimismo sosegada, respondió y dijo:/ - Al buen pagador no le duelen prendas (II, XIV)

don Quijote [...] con gentil denuedo dijo al Caballero de los Espejos: - -Si la mucha gana de pelear [...] no os gasta la cortesía, por ella os pido que alcéis la visera un poco (II, XIV)

la perspectiva misma del bachiller Sansón Carrasco; y así como la vio, en altas voces dijo:/ —iAcude, Sancho [...]! (II, XIV)

llegó el escudero del de los Espejos [...] y a grandes voces dijo:/ Mire vuesa merced lo que hace, señor don Quijote (II, XIV)

Y mirándole más y más Sancho, con voz admirativa y grande, dijo:/ - ¡Santa María, y valme! ¿Éste no es Tomé Cecial, mi vecino y compadre? (II, XIV)

[cuando don Quijote descubre los requesones en su celada] A lo que con gran flema y disimulación respondió Sancho:/ - $\mathrm{Si}$ son requesones, démelos vuesa merced, que yo me los comeré... (II, XVII)

se levantó en pie don Quijote, y en voz levantada, que parecía grito, asiendo con su mano la derecha de don Lorenzo, dijo:/ - iViven los cielos donde más altos están, mancebo generoso [..]! (II, XVIII)

oyeron a sus espaldas grandes voces, y una que decía:/ -Esperaos un poco, gente tan desconsiderada como presurosa (II, XXI)

- Oh santo Dios! — dijo a este tiempo dando una gran voz Sancho (II, XXIII) 
[un hombre] con voz levantada dijo:/ -Señor huésped, ¿hay posada? (II, XXV)

don Quijote [...], poniéndose en pie, en voz alta dijo:/ - No consentiré yo [...] (II, XXVI)

don Quijote [...] quiso aprovecharse de aquel silencio, y rompiendo el suyo, alzó la voz y dijo:/ - Buenos señores, cuan encarecidamente puedo, os suplico [...] (II, XXVII)

[don Quijote] con voz alta, dijo a Sancho:/_¿Ves? Allí, ¡oh amigo!, se descubre la ciudad castillo o fortaleza (II, XXIX)

Los molineros [...] Daban voces grandes, diciendo:/ —Demonios de hombres! ¡Dónde vais? (II, XXIX)

$\mathrm{Y}$ puesto en pie en el barco [don Quijote], con grandes voces comenzó a amenazar a los molineros: - Canalla malvada y peor aconsejada (II, XXIX)

don Quijote [...] con gran sosiego, como si no hubiera pasado nada por él, dijo [...] que él pagaría el barco (II, XXIX)

[don Quijote] alzando la voz, prosiguió diciendo, y mirando a las aceñas:/ -Amigos, cualesquiera que seáis, que en esa prisión quedáis encerrados (II, XXIX)

- Hijo de puta - [...] esto dijo [la dueña] en voz tan alta (II, XXXI) la dilación y pausas con que Sancho contaba su cuento (II, XXXI)

[don Quijote] haciendo una profunda reverencia a los duques, como que les pedía licencia para hablar, con voz reposada dijo a la canalla:/ —Hola, señores caballeros! Vuesas mercedes dejen al mancebo (II, XXXII)

Sancho [colgando de la encina y amenazado por el jabalí] comenzó a dar tantos gritos y a pedir socorro con tanto ahínco (II, XXXIV)

se levantó de su alto asiento el viejo venerable, y puesto en pie, dando una gran voz, dijo:/ - Yo soy el sabio Lirgandeo (II, XXXIV)

[el Caballero de la Barba Blanca] desencajó y sacó de ancho y dilatado pecho una voz grave y sonora, y poniendo los ojos en el duque, dijo:/ —Altísimo y poderoso señor [...] (II, XXXVI)

[don Quijote] tentó la clavija [de Clavileño], y apenas hubo puesto los dedos en ella cuando todas las dueñas y cuantos estaban presentes levantaron las voces, diciendo:/ —Dios te guíe, valeroso caballero! (II, XLI) 
[don Quijote] cerró tras sí la puerta, y hizo casi por fuerza que Sancho se sentase junto a él, y con reposada voz le dijo:/ - Infinitas gracias doy al cielo, Sancho amigo [...] (II, XLII)

una mujer asida fuertemente de un hombre [...], la cual venía dando grandes voces, diciendo:/ — ¡Justicia, señor gobernador [...]! (II, XLV)

la mujer [defendiéndose del hombre que le quería quitar la bolsa] [...] daba voces diciendo:/ — ¡Justicia de Dios y del mundo! (II, XLV)

don Quijote [...] poniendo mano a la espada comenzó a tirar estocadas por la reja y a decir a grandes voces:/ - ¡Afuera, malignos encantadores! (II, XLVI)

[cuando el gato se le agarra a la cara] don Quijote comenzó a dar los mayores gritos que pudo (II, XLVI)

[Altisidora, tras ser arañado don Quijote por el gato] le puso unas vendas por todo lo herido, y al ponérselas, con voz baja le dijo: [...] (II, XLVI)

Oyendo esto Sancho, se arrimó sobre el espaldar de la silla y miró de hito en hito al tal médico, y con voz grave le preguntó cómo se llamaba y dónde había estudiado (II, XLVII)

[doña Rodríguez, espantada al ver a don Quijote] dio una gran voz, diciendo:/ —iJesús! ¿Qué es lo que veo? (II, XLVIII)

el secretario, se llegó al oído del maestresala, y le dijo muy paso:/ - Sin duda alguna que a esta pobre doncella [...](II, XLIX)

saltando, corriendo y brincando, llegó al pueblo la muchacha, y antes de entrar en su casa dijo a voces desde la puerta:/ - Salga, madre Teresa, salga, salga (II, L)

Oyó el cielo su petición, y cuando menos lo esperaba, oyó voces que decían:/ - iVitoria, vitoria! (II, LIII)

habiéndole estado mirando uno de ellos con mucha atención, arremetió a él, echándole los brazos por la cintura, y en voz alta y muy castellana, dijo:/ - [...] ¿Es posible [...] mi buen vecino Sancho Panza? (II, LIV)

estándola mirando, oyó grandes voces dentro (II, LV)

Parecióle a don Quijote que oía la voz de Sancho Panza [...], y levantando la voz todo lo que pudo, dijo:/ — ¿Quién está allá abajo? (II, LV) 
y viéndole partir su buen escudero Sancho, dijo a grandes voces:/ ¡Dios te guíe, nata y flor de los andantes caballeros! (II, LVI)

Aunque Tosilo vio venir contra sí a don Quijote [...] con grandes voces, llamó al maese de campo (II, LVI)

Tosilos se llegó a donde doña Rodríguez estaba, y dijo a grandes voces:/ —Yo, señora [...] (II, LVI)

[al ver a Tosilos] doña Rodríguez y su hija, dando grandes voces, dijeron:/ —Éste es engaño, engaño es éste! (II, LVI)

alzados los manteles, con gran reposo alzó don Quijote la voz, y dijo:/ —Entre los pecados [...] (II, LVIII)

Sancho [...], dando una gran voz, dijo:/ — ¿Es posible que haya en el mundo personas que se atrevan a decir y a jurar que este mi señor es loco? (II, LVIII)

Puesto, pues, don Quijote en mitad del camino-como os he dicho-, hirió el aire con semejantes palabras: - ¡Oh vosotros pasajeros y viandantes, caballeros, escuderos [...] (II, LVIII)

Llegó el tropel de los lanceros, y uno de ellos [...] a grandes voces comenzó a decir a don Quijote:/ —iApártate, hombre del diablo, del camino [...]! (II, LVIII)

don Quijote [...] comenzó a correr tras la vacada, diciendo a voces:/ — ¡Deteneos y esperad, canalla malandrina [...]! (II, LVIII)

Oyendo decir esto los salteadores, levantaron la voz, diciendo:/ ¡Viva Roque Guinart muchos años, a pesar de los lladres que su perdición procuran! (II, LX)

don Quijote [...] viéndose apretar de requiebros, alzó la voz y dijo:/ -Fugite, partes adversae; (II, LXII)

El primero que se llegó al oído de la cabeza fue el mismo don Antonio, y díjole en voz sumisa, pero no tanto, que de todos no fuese oída:/ [...] (II, LXII)

[un caballero] llegándose a trecho que podía ser oído, en altas voces [...] dijo:/ - Insigne caballero y jamás como se debe alabado don Quijote de la Mancha [...] (II, LXIV)

don Quijote quedó suspenso y atónito [...] y con reposo y ademán severo le respondió:/ - Caballero de la Blanca Luna, cuyas hazañas hasta agora no han llegado a mi noticia [...] (II, LXIV) 
entró don Antonio, diciendo con muestras de grandísimo contento:/ —iAlbricias, señor don Quijote [...]! (II, LXV)

un hermoso mancebo[...] que al son de una harpa, que él mismo tocaba, cantó con suavísima y clara voz (II, LXIX)

[fingiendo que se azotaba] Volvió Sancho a su tarea [...] y alzando la voz, y dando un desaforado azote en una haya, dijo:/ -iAquí morirás, Sansón [...]! (II, LXXI)

Despertó [don Quijote] al cabo del tiempo dicho, y dando una gran voz, dijo:/ - iBendito sea el poderoso Dios, que tanto bien me ha hecho! (II, LXXIV)

\section{B. CALIFICADORES}

\section{Primera Parte}

[el ventero, armando caballero a don Quijote] diole [...] un gentil espaldarazo, siempre murmurando entre dientes, como que rezaba (I, III)

Don Quijote le preguntó [a una moza de la venta] cómo se llamaba [...]. Ella respondió con mucha humildad que se llamaba la Tolosa, y que era hija de un remendón natural de Toledo (I, III)

de la espesura de un bosque que allí estaba, salían unas voces delicadas, como de persona que se quejaba (I, IV)

Y viendo don Quijote lo que pasaba, con voz airada dijo:/ Descortés caballero, mal parece tomaros con quien defender no se puede (I, IV)

con muestras de grande sentimiento, se comenzó a volcar por la tierra y a decir con debilitado aliento lo mesmo que dicen decía el herido caballero del bosque:/ — ¿Dónde estás, señora mía,/ que no te duele mi mal?/ O no lo sabes, señora y eres falsa y desleal? (I, V)

[Vivaldo] leyendo en voz clara (I, XIII)

[después de ser apaleados] el primero que se resintió fue Sancho Panza; y hallándose junto a su señor, con voz enferma y lastimada, dijo:/— ¡Señor don Quijote! ¡Ah, señor don Quijote! (I, XV) 
— ¿Qué quieres, Sancho hermano?--respondió don Quijote con el mesmo tono afeminado y doliente que Sancho (I, XV)

[don Quijote, agarrando a la criada de la venta en la oscuridad] Y, teniéndola bien asida, con voz amorosa y baja le comenzó a decir:-l Quisiera hallarme en términos, fermosa y alta señora, de poder pagar tamaña merced como la que con la vista de vuestra gran fermosura me habedes hecho [...] (I, XVI)

descubrieron muchos encamisados [y Sancho] comenzó a dar diente con diente, como quien tiene frío de cuartana; y creció más el batir y dentellear (I, XIX)

Don Quijote [oliendo los vapores de Sancho y apretándose las narices], con tono algo gangoso, dijo: -Paréceme, Sancho, que tienes mucho miedo (I, XX)

En llegando el mancebo a ellos, los saludó con una voz desentonada y bronca, pero con mucha cortesía (I, XXIII) (I, XXIV)

— iEso no, ¡voto a tal! -respondió con mucha cólera don Quijote

Estando, pues, los dos allí sosegados y a la sombra, llegó a sus oídos una voz [de hombre], que sin acompañarle son de algún otro instrumento, dulce y regaladamente sonaba (I, XXVII)

en acabando de decirme esto [a Luscinda] se le llenaron los ojos de lágrimas y un nudo se le atravesó en la garganta, que no le dejaba hablar palabra de otras muchas que me pareció que procuraba decirme (I, XXVII)

una señora muy hermosa le llamó desde una ventana, los ojos llenos de lágrimas, y con mucha priesa le dijo: - Hermano, si sois cristiano, como parecéis, por amor de Dios [...] (I, XXVII)

dijo [Luscinda, cuando el cura los casaba] con voz desmayada y flaca: —Sí quiero», y lo mismo dijo don Fernando (I, XXVII)

una voz [...], que en lastimados acentos oyeron que decía lo que se dirá $[\ldots]$ (I, XXVII)

así como el cura comenzó a prevenirse para consolar a Cardenio, lo impidió una voz que llegó a sus oídos, que, con tristes acentos, decía desta manera:/ — iAy Dios! [...] (I, XXVIII)

[Dorotea] con tan suelta lengua, con voz tan suave, que no menos les admiró su discreción que su hermosura (I, XXVIII) 
a quien pienso [...] tajar la cabeza soberbia con los filos desta... no quiero decir buena espada, merced a Ginés de Pasamonte, que me llevó la mía./ Esto dijo [don Quijote] entre dientes (I, XXX)

Éstas y otras razones decía la ventera con grande enojo (I, XXXV)

y en oyéndolo don Quijote, se volvió a Sancho, y con muestras de mucho enojo, le dijo: - Ahora te digo, Sanchuelo, que eres el mayor bellacuelo que hay en España (I, XXXVII)

¡Voto...-y miró al cielo y apretó los dientes-que estoy por hacer un estrago en ti [...]! (I, XXXVII)

[la mora] dijo con mucha priesa, llena de congoja y donaire:/ - ¡No, no Zoraida: María, María! (I, XXXVII)

uno de los cuadrilleros [...] que había oído la pendencia y quistión, lleno de cólera y de enfado, dijo:/ - Tan albarda es como mi padre; y el que otra cosa ha dicho o dijere debe de estar hecho uva [borracho] (I, XLV)

Y al acabar de la profecía [el barbero], alzó la voz de punto, y diminuyóla después, con tan tierno acento, que aun los sabidores de la burla estuvieron por creer que era verdad (I, XLV)

Digo que fue tanto [el enojo de don Quijote], que, con voz atropellada y tartamuda lengua, lanzando vivo fuego por los ojos, dijo:/ ¡Oh bellaco villano $[\ldots]_{i}$ (I, XLVI)

se oyó una voz temerosa, todo cuanto la supo formar el barbero [...], que decía:/ -jOh Caballero de la Triste Figura! No te dé afincamiento la prisión en que vas, porque así conviene [...] (I, XLVI)

[don Quijote, acercándose a la procesión] con turbada y ronca voz, dijo:/ - Vosotros, que, quizá por no ser buenos, os encubrís los rostros, atended y escuchad lo que deciros quiero (I, LII)

Con las voces y gemidos de Sancho revivió don Quijote (I, LII)

Segunda Parte

[Recuerda] si te repite la respuesta que te diere dos o tres veces; si la muda de blanda en áspera, de aceda [áspera] en amorosa (II, X) 
[la labradora] toda desgraciada [sin gracia] y mohina, dijo (II, X)

con voz doliente y lastimada, dijo [el Caballero del Bosque]:/ ${ }_{\mathrm{i}} \mathrm{O} \mathrm{Oh}$ la más hermosa y la más ingrata mujer del orbe! (II, XII)

Sancho, con lágrima en los ojos le suplicó [a don Quijote] desistiese de tal empresa (II, XVII)

[Basilio, el falso suicida en las bodas de Camacho] Llegó, en fin, cansado y sin aliento, y puesto delante de la desposada [...] mudada la color, puestos los ojos en Quiteria, con voz tremente y ronca estas razones dijo: (II, XXI)

[Basilio, el falso suicida en las bodas de Camacho] con voz doliente y desmayada [...] [fingiendo morir] ya los ojos vueltos, el aliento corto y apresurado, murmurando entre los dientes el nombre de Quiteria (II, XXI)

asidos de la mano Basilio y Quiteria, el cura, tierno y lloroso, les echó la bendición (II, XXI)

las palabras de don Quijote [...] las decía como si con dolor inmenso las sacara de las entrañas (II, XXII)

el venerable Montesinos, se puso de rodillas ante el lastimado caballero [Durandarte], $\mathrm{y}$, con lágrimas en los ojos, le dijo:/ —Ya, señor Durandarte, carísimo primo mío [...] (II, XXIII)

«Y cuando así no sea», respondió el lastimado Durandarte con voz desmayada y baja, «cuando así no sea, joh primo!, digo, paciencia y barajar» (II, XXIII)

se llegó a mí [don Quijote] una de las compañeras de la sin ventura Dulcinea, y llenos los ojos de lágrimas, con turbada y baja voz, me dijo:/ -Mi señora Dulcinea del Toboso besa a vuestra merced las manos y suplica [...] (II, XXIII)

don Quijote [...] con asaz cólera le dijo:/ — ¡Tan en hora mala supiste rebuznar, Sancho! (II, XXVIII)

Sancho [...], en tanto que tales vituperios le decía [don Quijote] compungióse de manera que le vinieron las lágrimas a los ojos, y con voz dolorida y enferma le dijo:/-Señor mío, yo confieso que para ser del todo asno no me falta más que la cola (II, XXVIII)

Y en esto [Sancho], comenzó a llorar tan amargamente, que don Quijote, mohíno y colérico, le dijo:/ — ¿De qué temes, cobarde criatura? ¿De qué lloras, corazón de mantequillas? (II, XXIX) 

XXXI)

- Hijo de puta — dijo la dueña, toda ya encendida en cólera (II,

[don Quijote] con mucha cólera, hablando con el duque, le dijo:/ Vuestra Excelencia [...] (II, XXXI)

en pie don Quijote, temblando de los pies a la cabeza como azogado, con presurosa y turbada lengua dijo:/ $-\mathrm{El}$ lugar donde estoy, y la presencia ante quien me hallo [...] (II, XXXII)

A lo que respondió el correo con voz horrísona y desenfadada:/-Yo soy el diablo (II, XXXIV)

el que venía sentado en el tronco [con el carro] dijo con voz más ronca y más endiablada:/ - Yo soy Arcalau, el encantador (II, XXXIV)

puesta en pie esta muerte viva, con voz algo dormida y con lengua no muy despierta, comenzó a decir desta manera:/ - Yo soy Merlín aquel que las historias/ dicen que tuve por mi padre al diablo (II, XXXV)

[la ninfa] con un desenfado varonil y con una voz no muy adamada [femenina] [...], dijo:/ — iOh, malaventurado escudero, alma de cántaro, corazón de alcornoque, de entrañas guijeñas y apedernaladas! [...] (II, XXXV)

Ella [la Dolorida], puesta de rodillas en el suelo, con voz antes basta y ronca que sutil y delicada, dijo:/ - Vuestras grandezas sean servidas de no hacer tanta cortesía a este su criado, digo, a esta su criada (II, XXXVIII)

[el hombre a quien juzga Sancho] todo turbado, respondió:/ - Señores, yo soy un pobre ganadero de ganado de cerda, y esta manana salía deste lugar de vender, con perdón sea dicho, cuatro puercos (II, XLV)

Sancho [...] miró de hito en hito al tal médico, y con voz grave le preguntó cómo se llamaba (II, XLVII)

respondió Sancho, todo encendido en cólera:/ - Pues señor doctor Pedro Recio de Mal Agüero [...] (II, XLVII)

Don Quijote [...] afinándola [la vihuela] lo mejor que pudo, escupió y remondóse el pecho [carraspeó], y luego con una voz ronquilla, aunque entonada, cantó el siguiente romance [...]:/ —-Suelen las fuerzas del amor/ sacar de quicio a las almas (II, XLVI) 
[al caerse doña Rodríguez, a quien don Quijote toma por visión] Don Quijote, temeroso, comenzó a decir:/ - Conjúrote, fantasma, o lo que eres (II, XLVIII)

La abrumada dueña, que oyó conjurarse, por su temor coligió el de don Quijote, y con voz afligida y baja le respondió:/ - Señor don Quijote, si es que acaso vuestra merced es don Quijote, yo no soy fantasma (II, XLVIII)

—Levántenme-dijo con voz doliente el dolorido Sancho (II, LIII)

alzó la voz la desenvuelta y discreta Altisidora, y en son lastimero dijo:/ -Escucha, mal caballero;/ detén un poco las riendas;/ no fatigues las ijadas/ de tu mal regida bestia (II, LVII)

Volvióse don Quijote a Sancho, y encendido el rostro y colérico, le dijo:/ — ¿Es posible, ¿oh Sancho!, que haya en todo el orbe alguna persona que diga que no eres tonto [...]? (II, LVIII)

Hallaron a don Vicente en los brazos de sus criados, a quien con cansada y debilitada voz rogaba que le dejasen allí morir (II, LX)

El primero que se llegó al oído de la cabeza fue el mismo don Antonio, y díjole en voz sumisa, pero no tanto, que de todos no fuese oída:/ -Dime, cabeza, por la virtud que en ti se encierra, ¿qué pensamientos tengo yo agora (II, LXII)

Don Quijote [vencido por el de la Blanca Luna] con voz debilitada y enferma, dijo:/ - [...]. Aprieta, caballero, la lanza, y quítame la vida, pues me has quitado la honra (II, LXIV)

No las hubo visto Sancho [a las cuatro dueñas con los brazos en alto] cuando bramando como un toro, dijo:/ -Bien podré yo dejarme manosear de todo el mundo; pero consentir que me toquen dueñas, ¡eso no! (II, LXIX)

Sentóse Altisidora en una silla, junto a su cabecera [de don Quijote], y después de haber dado un gran suspiro ${ }^{9}$, con voz tierna y debilitada le dijo:/ - Cuando las mujeres principales y las recatadas doncellas atropellan por la honra [...] (II, LXX)

${ }^{9}$ Nótese la abundancia de los suspiros, de los cuales, sin embargo, sólo 12 son femeninos; de los otros 23, 11 se los oímos a don Quijote, y del resto, son falsos en dos casos (Fernando engañando a Dorotea y Sancho fingiendo que se azotaba). 
oyendo lo cual Altisidora, mostrando enojarse y alterarse, le dijo [a don Quijote]:/ — ¿Vive el Señor, don bacallao, alma de almirez, cuesco de dátil [...] (II, LXX)

\section{DIFERENCIADORES}

\section{Primera Parte}

Oyendo lo cual, mi amigo, dándose una palmada en la frente y disparando en una carga de risa, me dijo:/ - Por Dios, hermano, que ahora me acabo de desengañar de un engaño (I, 'Prólogo')

[Don Quijote, tras ser apaleado por los mercaderes] no se podía tener sobre el borrico, y de cuando en cuando daba unos suspiros que los ponía en el cielo (I, V)

[el muchacho] sin dejar la risa ${ }^{10}$, dijo:/ -Está, como he dicho, aquí en el margen escrito esto: «Esta Dulcinea del Toboso [...] tuvo la mejor mano para salar puercos que otra mujer de toda la Mancha (I, IX)

mucho mejor me sabe lo que me como en mi rincón sin melindres ni respetos, aunque sea pan y cebolla, que los gallipavos de otras mesas donde me sea forzoso mascar despacio, beber poco, limpiarme a menudo, no estornudar ni toser si me viene en gana (I, XI)

Aquí dio un gran suspiro don Quijote (I, XIII)

Don Quijote y Sancho, que la paliza de Rocinante habían visto, llegaban ijadeando, y dijo don Quijote [jadeando] a Sancho:/ -A lo que yo veo, amigo Sancho, estos no son caballeros, sino gente soez y de baja ralea (I, XV)

$\mathrm{Y}$ [Sancho] despidiendo treinta ayes y sesenta sospiros (I, XV)

mirábale también [a don Quijote] la hija del ventero, y él también no quitaba los ojos della, y de vez en cuando arrojaba un sospiro que parecía que le arrancaba de lo profundo de sus entrañas

10 En éste ejemplo y otros similares se trata de discurso reído, a través de toda la intervención, mientras que en otros casos la risa alterna con las palabras. 
Cuando Sancho oyó las palabras de su amo, comenzó a llorar con la mayor ternura del mundo, y a decille: - Señor, yo no sé por qué quiere vuestra merced acometer esta tan temorosa aventura $(\mathrm{I}, \mathrm{XX})^{11}$

tornó a llorar Sancho oyendo de nuevo las lastimeras razones de su buen señor (I, XX)

Miró también don Quijote a Sancho, y viole que tenía los carrillos hinchados, y la boca llena de risa, con evidentes señales de querer reventar con ella, y no pudo su melancolía tanto con él, que a la vista de Sancho pudiese dejar de reírse; y [...] Sancho [...] soltó la presa de tal manera que tuvo necesidad de apretarse las ijadas con los puños, por no reventar riendo (I, XX)

Cuando Sancho oyó llamar a bacía celada, no pudo tener la risa; más vínosele a las mientes la cólera de su amo, y calló en la mitad della (I, XXI)

Sospirará él, desmayaráse ella [la princesa], traerá agua la doncella (I, XXI)

[Sancho Panza, al despedirse de su señor] pidió la bendición a su señor, $\mathrm{y}$, no sin muchas lágrimas de entrambos, se despidió dél (I, XXV)

En esto [escribir versos don Quijote], y en suspirar, y en llamar a los faunos y silvanos de aquellos bosques [...] se entretenía [...] Y será bien dejalle envuelto entre suspiros y versos (I, XXVI)

El canto [de Cardenio] se acabó con un profundo suspiro (I, XXVII)

la noche que precedió al triste día de mi partida [de Cardenio], ella [Luscinda] lloró, gimió y suspiró (I, XXVII)

volvió [don Fernando, engañando a Dorotea] a humedecer sus ojos y a acrecentar sus suspiros, apretóme más entre sus brazos (I, XXVIII)

[don Quijote] desnudo, en camisa, flaco, amarillo y muerto de hambre, y suspirando por su señora Dulcinea (I, XXIX)

[Andrés, reconociéndole] arremetió a don Quijote y, abrazándole por las piernas, comenzó a llorar (I, XXXI)

11 Aquí, y en otros ejemplos, se trata de discurso llorado - y así ha de leerse-, mientras que en otros pasajes alterna el llanto con la palabra. Obsérvese también que se dan 18 casos de llanto femenino frente a 14 masculinos (de los cuales 11 corresponden a Sancho). 
Tomóle en esto a Camila un fuerte desmayo $\mathrm{y}$, arrojándose encima de una cama que allí estaba, comenzó Leonela a llorar muy amargamente y a decir:/ — iAy, desdichada de mí [...]! (I, XXXIV)

[Anselmo] acosado de sus pensamientos, le fue forzoso apearse y arrendar su caballo a un árbol, a cuyo tronco se dejó caer, dando tiernos y dolorosos suspiros (I, XXXV)

al sentarse la mujer [Dorotea] en la silla dio un profundo suspiro, y dejó caer los brazos, como persona enferma y desmayada (I, XXXVI)

en todo el camino no le he visto el rostro; suspirar sí la he oído muchas veces, y dar unos gemidos, que parece que con cada uno dellos quiere dar el alma (I, XXXVI)

todos caminan en tanto silencio, que es maravilla; porque no se oye entre ellos otra cosa que los suspiros y sollozos de la pobre señora (I, XXXVI)

[Dorotea] como había oído suspirar a la embozada, movida de natural compasión, se llegó a ella (I, XXXVI)

[Luscinda] había conocido en el suspiro a Cardenio (I, XXXVI)

[Dorotea] se levantó y se fue a hincar de rodillas a sus pies [don Fernando], y derramando mucha cantidad de hermosas y lastimeras lágrimas, así le comenzó a decir:/ —Si ya no es, señor mío, que los rayos deste sol que en tus brazos eclipsados tienes te quitan y ofuscan los de tus ojos, ya habrás echado de ver [que soy Dorotea] (I, XXXVI)

Éstas y otras razones dijo la lastimada Dorotea, con tanto sentimiento y lágrimas (I, XXXVI)

[Dorotea, después de hablar llorando, dio] principio a tantos sollozos y suspiros (I, XXXVI)

Luscinda [..] después de vuelta en sí, no había hecho otra cosa sino llorar y suspirar, sin hablar palabra alguna (I, XXXVI)

Con tantas lágrimas y con muestras de tanto arrepentimiento dijo esto el renegado [...] (I, XL)

[el padre de Zoraida] la arrimó a su pecho, y ella, dando un suspiro y aun no enjutos los ojos de lágrimas [...] (I, XLI)

Él, como vio allí a su hija [Zoraida], comenzó a suspirar tiernísimamente, y más cuando vio que yo estrechamente la tenía abrazada (I, XLI) 
el capitán [..] viendo que ya el cura había llegado al fin de su cuento, dando un gran suspiro y llenándosele los ojos de agua, dijo:/ — $\mathrm{iOh}$ señor, si supiésedes las nuevas que me habéis contado, y cómo me tocan [...] (I, XLII)

allí la cristiana hermosa y la mora hermosísima renovaron [al abrazarse] las lágrimas de todos (I, XLII)

aquí dio fin la voz [del mozo de mulas], y principio a nuevos sollozos de Clara (I, XLIII)

don Quijote estaba a caballo, recostado sobre su lanzón, dando de cuando en cuando tan dolientes y profundos suspiros, que parecía que con cada uno se le arrancaba el alma (I, XLIII)

el mozo, asiéndole fuertemente de las manos, como en señal de que algún gran dolor le apretaba el corazón, y derramando lágrimas en grande abundancia, le dijo:/ - Señor mío, yo no sé deciros otra cosa sino que [quiero casarme con vuestra hija] (I, XLIV)

oyeron que Sancho Panza, con lágrimas en los ojos, decía:/ — iOh flor de la caballería, que con sólo un garrotazo acabaste la carrera de tus bien gastados años! (I, LII)

Sancho no hizo otra cosa que arrojarse sobre el cuerpo de su señor, haciendo sobre él el más doloroso y risueño llanto del mundo, creyendo que estaba muerto (I, LII)

\section{Segunda Parte}

[don Quijote] sospirando y sin mirar lo que decía [...], dijo:/ — $\mathrm{OH}$ dulces prendas, por mí mal halladas [...]! (II, XVIII)

[Sancho] en acabando de beber [de la bota], dejó caer la cabeza a un lado, y dando un gran suspiro, dijo:/ — iOh hideputa, bellaco, y cómo es católico! (II, XIII)

asidos de las manos Basilio y Quiteria, el cura, tierno y lloroso, les echó la bendición (II, XXI)

el venerable Montesinos, se puso de rodillas ante el lastimado caballero [Durandarte], y, con lágrimas en los ojos, le dijo:/ — «a, señor Durandarte, carísimo primo mío, ya hice lo que mandaste [...]» (II, XXIII) 
$\mathrm{Y}$ en esto [Sancho], comenzó a llorar tan amargamente, que don Quijote, mohíno y colérico, le dijo:/ — ¿De qué temes, cobarde criatura? (II, XXIX)

impedido de la risa que su impertinente cólera [de Sancho] le había causado (II, XXXII)

a ellos [los duques] les retozaba la cólera y la risa en el cuerpo (II, XXXII)

Sospiró don Quijote oyendo lo que la duquesa mandaba (II, XXXII)

No pudo la duquesa tener la risa oyendo la simplicidad de su dueña (II, XXXIII)

Las razones de Sancho renovaron en la duquesa la risa y el contento (II, XXXIII)

Reventaban de risa con estas cosas los duques (II, XXXVIII)

Riéronse todos y la Dolorida prosiguió (II, XL)

Dijo esto con tanto sentimiento la Trifaldi, que sacó las lágrimas de los ojos de todos los circunstantes (II, XL)

Al despedirse de los duques [Sancho], les besó las manos, y tomó la bendición de su señor, que se la dio con lágrimas, y Sancho la recibió con pucheritos (II, XLIV)

[Claudia, al morir su esposo] rompió los aires con suspiros, hirió los cielos con quejas, maltrató sus cabellos (II, LX)

Ten cuenta, Sancho, de no mascar a dos carrillos, ni de erutar delante de nadie (II, XLIII)

don Quijote [...] para dar a entender que allí estaba, dio un fingido estornudo (II, XLIV)

[tras hablarle Altisidora amorosamente] No respondió don Quijote otra palabra si no fue dar un profundo suspiro (II, XLVI

que si con ello no rieres, por lo menos desplegarías los labios con risa de jimia [sonrisa de mona] (II, XLIV)

[don Quijote] para dar a entender que allí estaba, dio un fingido estornudo (II, XLIV)

[don Quijote] dando un gran suspiro, dijo entre sí:/ — iQue tengo de ser tan desdichado andante, que no ha de haber doncella que me mire que de mí no se enamore...i (II, XLIV) 
A todo esto [las bromas cuando está cantando] no respondió don Quijote otra palabra si no fue dar un profundo suspiro y luego se tendió en su lecho (II, XLVI)

Y en esto [doña Rodríguez] comenzó a llorar tiernamente, y dijo:/ -Perdóneme vuestra merced, señor don Quijote (II, XLVIII)

Y en esto [la hija de Pedro Pérez Mazorca], comenzó a llorar tiernamente (II, XLIX)

[la hija de Pedro Pérez Mazorca] entre interrotos sollozos y mal formados suspiros, dijo:/ - No es otra mi desgracia, ni mi infortunio es otro sino que [...] (II,XLIX)

Y [la hija de Pedro Pérez Mazorca] tornó a renovar el llanto (II, XLIX)

[una mujer] tendida de largo a largo, la boca cosida con los pies de don Quijote, y daba unos gemidos tan tristes, $y$ tan profundos, $y$ tan dolorosos (II, LII)

Sentóse Altisidora en una silla, junto a su cabecera [de don Quijote], y después de haber dado un gran suspiro, con voz tierna y debilitada le dijo: [...] (II, LXX)

Abrazáronle todos y él [Sancho], llorando, abrazó a todos (II, LIII)

Tantas y tan tristes eran las quejas de Claudia, que sacaron las lágrimas de los ojos de Roque (II, LX)

un anciano [...] apenas dio fin a su plática la morisca, cuando él se arrojó a sus pies, $y$ abrazado dellos, con interrumpidas palabras de mil sollozos y suspiros, le dijo:/-iOh Ana Félix, desdichada hija mía! (II, LXIII)

Hubo lágrimas, hubo suspiros, desmayos y sollozos al despedirse don Gregorio de Ana Félix (II, LXV)

Rióse el lacayo [de que don Quijote lo tomase por encantado] (II, LXVI)

Don Quijote [...] al son de sus mesmos suspiros, cantó de esa suerte [...]/ Cada verso déstos acompañaba con muchos suspiros y no pocas lágrimas (II, LXVIII)

Pero el socarrón [Sancho] dejó de dárselos [los azotes] en las espaldas, y daba en los árboles, con unos suspiros de vez en cuando, que parecía que con cada uno de ellos se le arrancaba el alma (II, LXXI) 
Elena [...] se reía a socapa y a lo socarrón (II, LXXI)

Estas nuevas [que don Quijote se moría] dieron un terrible empujón a los ojos preñados de ama, sobrina, y de Sancho Panza [...] los hizo reventar las lágrimas de los ojos y mil profundos suspiros del pecho (II, LXXIV)

\section{ALTERNANTES}

\section{Primera Parte}

oyeron un silbo como de pastor (I, XXIII)

— iTa, ta! - dijo el cura-[...] Para mi santiguada que yo los queme [los libros] antes que llegue la noche (I, V)

¡Ta, ta!-dijo Sancho-. ¿Que la hija de Lorenzo Corchuelo [...]?/ —Ésa es-dijo don Quijote (I, XXV)

la música se había vuelto en sollozos y en lastimeros ayes (I, XXVII)

descubrieron muchos encamisados, cuya temerosa visión de todo punto remató el ánimo de Sancho Panza, el cual comenzó a dar diente con diente, como quien tiene frío de cuartana; y creció más el batir y dentellear cuando distintamente vieron lo que era (I, XIX)

[Dorotea] después de haberse puesto bien en la silla y prevenídose con toser y hacer otros ademanes, con mucho donaire comenzó a decir desta manera:/ -Primeramente, quiero que vuestras mercedes sepan, señores míos que a mí me llaman... [...] (I, XXX)

apenas le hubo conocido [Dorotea a Fernando], cuando, arrojando de lo íntimo de sus entrañas un luengo y tristísimo ;ay!, se dejó caer de espaldas desmayada (I, XXXVI)

y de un revés, ¡zas!, le derribé la cabeza en el suelo [don Quijote al gigante] (I, XXXVII)

la hija de la ventera le comenzó a cecear [iCe, ce!] y a decirle:/ Señor mío, lléguese acá la vuestra merced (I, XLIII) 


\section{Segunda Parte}

Oyéronse en esto grandes alaridos y llantos, acompañados de profundos gemidos y angustiados sollozos (II, XXIII)

De cuando en cuando daba Sancho unos ayes profundísimos y unos gemidos dolorosos (II, XXVIII)

[Sancho] puesta la mano en las narices, comenzó a rebuznar tan reciamente, que todos cercanos valles retumbaron (II, XXVII)

Luego se oyeron infinitos lelilíes [gritos de guerra de los moros], al uso de moros cuando entran en las batallas (II, XXXIV)

se reiteraban los lililíes agarenos (II, XXXIV)

cuando te hicieren tus, tus [llamada a un perro], con alguna buena dádiva, envásala (II, L)

toda la chusma le saludó como es usanza cuando una persona principal entra en la galera, diciendo: ‘ $i \mathrm{Hu}$, hu, hu!' tres veces (II, LXIII)

¡Esas burlas, a un cuñado [a otro]; que yo soy perro viejo, y no hay conmigo tus, tus! (II, LXIX)

Estas nuevas [que don Quijote se moría] dieron un terrible empujón a los ojos preñados de ama, sobrina, y de Sancho Panza [...] los hizo reventar las lágrimas de los ojos y mil profundos suspiros del pecho (II, LXXIV)

su ama, su sobrina y su escudero, los cuales comenzaron a llorar tiernamente, como si ya le tuvieran muerto delante [a don Quijote] (II, LXXIV) 